\title{
Hubungan Length of Stay dan Karakteristik Pasien (Jenis Kelamin dan Umur) Terhadap Biaya Pasien JKN Acute Infarction Myocardial di Rumah Sakit Bethesda Yogyakarta 2016
}

\author{
Lia Suci Kriswanti ${ }^{1}$, Sugeng ${ }^{2}$ \\ D3 Rekam Medis Universitas Gadjah Mada1, RSUP dr Sardjito Yogyakarta ${ }^{2}$ \\ Liasuci25@gmail.com ${ }^{1}$, Sugeng.icm@gmail.com²
}

\begin{abstract}
ABSTRAK
Latar Belakang: Undang-Undang nomor 29 tahun 2004 tentang praktik kedokteran pasal 49 ayat 1 bahwa setiap dokter atau dokter gigi dalam melaksanakan praktik kedokteran atau kedokteran gigi wajib menyelenggarakan kendali mutu dan kendali biaya. Hal ini mendorong peneliti untuk melihat hubungan antara length of stay dan karakteristik pasien (umur dan jenis kelamin) terhadap biaya perawatan sebagai kendali mutu dan biaya.

Tujuan: Mengetahui hubungan antara length of stay dan karakteristik pasien (jenis kelamin dan umur) terhadap biaya perawatan pasien JKN acute infarction myocardial di Rumah Sakit Bethesda 2016.

Metode Penelitian: Jenis penelitian descriptive dengan pendekatan kuantitatif. Rancangan cross sectional. Teknik pengambilan data studi dokumentasi. Sampel berjumlah 38 berkas. Teknik sampling purposive sample.

Hasil: Dari sampel sebanyak 38 berkas, terdapat jenis kelamin laki-laki 35 orang (92\%), perempuan 3 orang $(8 \%)$. Umur kurang dari sama dengan 65 tahun 24 orang $(63 \%)$, umur lebih dari 65 tahun 14 orang $(37 \%)$. Length of stay kurang dari sama dengan 7 hari 28 orang $(74 \%)$, length of stay lebih dari 7 hari 10 orang (26\%). Dari hasil uji statistik Chi-squared Test, diperoleh nilai p-value length of stay sebesar 0,04342 yang menunjukkan bahwa $\mathrm{H}_{\mathrm{o}}$ diterima dengan nilai Odd Ratio(OR) sebesar 4,783396

Kesimpulan: Terdapat hubungan antara Length Of Stay terhadap Biaya Pasien JKN Acute Infarction Myocardial di Rumah Sakit Bethesda Yogyakarta 2016. Peluang length of stay yang tepat menyebabkan keakuratan biaya perawatan 4,78 kali lebih besar dibandingkan length of stay yang tidak tepat.

Kata kunci: length of stay, biaya, acute infarction myocardial.
\end{abstract}

ABSTRACT
Background: Law number 29 of 2004 on medical practice Article 49 paragraph 1 that every physician or dentist in performing medical or dental practice shall conduct quality control and cost control. This encourages researchers to see the relationship between length of stay and patient characteristics (age and sex) on maintenance costs as quality and cost control.

Objective: To examine the relationship between length of stay and patient characteristics (sex and age) on the cost of treating JKN acute infarction myocardial patients at Bethesda Hospital 2016. Methods: Type of descriptive research with quantitative approach. Cross sectional design. Technique of data retrieval study documentation. The sample is 38 files. Sampling technique purposive sample.

Results: From the sample of 38 files, there were 35 men (92\%), female $3(8 \%)$. Age less than 65 years old 28 people (63\%), age more than 65 years 10 people (37\%). Length of stay less than equal to 7 days 24 people (74\%), length of stay more than 7 days 10 people (26\%). From result of Chi-squared Test statistic test, obtained p-value length of stay of 0,04342 indicating that Ho accepted with value of Odd Ratio (OR) equal to 4,783396 .

Conclusion: There is a relationship between Length Of Stay to JKN Acute Infarction Myocardial Patient Cost at Bethesda Hospital Yogyakarta, 2016. Appropriate length of stay opportunities cause the accuracy of maintenance cost 4.78 times greater than the length of stay is not appropriate.

Keywords: length of stay, cost, acute infarction myocardial. 


\section{PENDAHULUAN}

Pembangunan

meningkatakan

kesehatan untuk derajat kesehatan masyarakat yang setinggi- tingginya dan setiap orang berkewajiban turut serta dalan program Jaminan Kesehatan Nasional. Setiap dokter atau dokter gigi dalam melaksanakan praktik kedokteran atau kedokteran gigi wajib menyelenggarakan kendali mutu dan kendali biaya (Undangundang No. 29, 2004).

Tarif INA-CBG adalah besaran pembayaran klaim oleh BPJS kesehatan kepada Fasilitas Kesehatan Rujukan Tingkat Lanjutan. Petunjuk teknis sistem INA-CBGS adalah sistem casemix adalah pengelompokan diagnosis dan prosedur dengan mengacu pada ciri klinis dan penggunaan sumber daya/biaya perawatan yang mirip/sama dengan menggunakan software grouper (Peraturan Menteri Kesehatan Nomor 27).

Setiap rumah sakit harus memiliki organisasi yang efektif, efisien, dan akuntabel. BPJS mengembangkan sistem pelayanan kesehatan, sistem kendali mutu pelayanan, dan sistem pembayaran pelayanan, kesehatan untuk meningkatkan efisiensi dan efektivitas. Pada survei awal yang telah di lakukan, berdasarkan data 2016, penyakit Acute Infarction Myocardial tergolong dalam daftar 10 penyakit kardiovaskuler terbanyak rawat inap sehingga peneliti tertarik untuk mengetahui hubungan length of stay dan karakteristik pasien terhadap biaya perawatan. Tujuan utama dalam pelayanan kesehatan adalah menghasilkan outcome yang menguntungkan bagi pasien, provider, dan masyarakat. Rumusan masalah adalah “Bagaimana Hubungan Length Of Stay dan Karakteristik Pasien (Jenis Kelamin dan Umur) terhadap Biaya Pasien JKN Acute Infarction Myocardial di Rumah Sakit Bethesda Yogyakarta 2016?".

Tujuan penelitian ini untuk mengetahui hubungan length of stay dan karakteristik pasien (jenis kelamin dan umur) terhadap biaya pasien JKN Acute Infarction Myocardial di RS Bethesda Yogyakarta
2016. Manfaat bagi rumah sakit untuk meningkatkan mutu standar pelayanan kesehatan sehingga bisa menjadi alat perencanaan anggaran rumah sakit dan menetapkan biaya yang kompetitif dan bisa diterima masyarakat.

\section{METODE}

Jenis penelitian yang digunakan adalah penelitian survei analitik dengan pendekatan kuantitatif. Metode yang digunakan adalah metode studi dokumentasi. Rancangan penelitian yang digunakan adalah rancangan penelitian cross-sectional. Populasi dalam penelitian ini adalah seluruh pasien yang terdiagnosis Acute Infarction Myocardial yang terdiagnosis pertama kali di Rumah Sakit Bethesda Yogyakarta. Sampel dalam penelitian ini adalah 38 berkas. Peneliti menggunakan teknik purposive sampling dalam pengambilan data. Studi pendahuluan dilakukan november 2016 dan penelitian dilakukan Januari-Maret 2017.

Variabel bebas atau independent variable dalam penelitian ini yaitu length of stay, jenis kelamin dan umur pasien. Variabel terikat atau dependent variable atau variabel tidak bebas yaitu biaya perawatan pasien. Teknik pengambilan data merupakan langkah yang paling strategis dalam penelitian karena tujuan utama dari penelitian adalah mendapatkan data. Teknik pengambilan data yaitu studi dokumentasi. Instrumen penelitian menggunakan checklist studi dokumentasi dan alat tulis. Teknik Validitas sudah valid karena telah diisi di bagian berkas rekam medis dan tersimpan dalam database rekam medis. Reliabilitas sudah sesuai. Teknik analisis pengolahan data disesuaikan dengan alat uji statistik yang dikendaki. Proposisi yaitu univariat dan bivariate. Pengolahan data untuk penelitian dengan pendekatan kuantitatif. Analisis data merupakan proses pengolahan, penyajian, interpretasi, dan analisis data yang diperoleh dari lapangan. Analisis data memiliki beberapa tujuan, yaitu memperoleh gambaran dari hasil penelitian. 
Semua hipotesis untuk kategorik tidak berpasangan menggunakan Chi-square bila memenuhi syarat (Hatta, 2013).

\section{HASIL DAN PEMBAHASAN}

Data yang telah dikumpulkan dari lapangan disajikan dalam tabel.

Hasil dari penelitian ini adalah:

1. Persentase Length Of Stay Pasien JKN Acute Infarction Myocardial

Tabel 1. Distribusi responden length of stay pasien JKN Acute Infarction Myocardial di

Rumah Sakit Bethesda Yogyakarta 2016

\begin{tabular}{llll}
\hline No & Length Of Stay & N & $\%$ \\
\hline 1. & $\begin{array}{l}\text { Kurang dari sama } \\
\text { dengan 7 hari }\end{array}$ & 28 & $74 \%$ \\
2. & $\begin{array}{l}\text { Lebih dari 7 hari } \\
\text { Total }\end{array}$ & 10 & $26 \%$ \\
\hline & 38 & $100 \%$ \\
\hline
\end{tabular}

Dari Tabel 1 diperoleh hasil bahwa length of stay kurang dari sama dengan 7 hari sebesar $28(74 \%)$ dan hasil length of stay lebih dari 7 hari sebesar 10 (26\%).

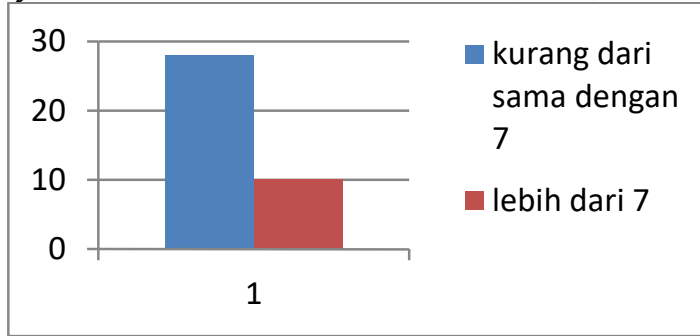

Gambar 1. Persentase length of stay pasien JKN Acute Infarction Myocardial di Rumah Sakit

Bethesda Yogyakarta 2016

Sumber: Data primer, 2016.

2. Persentase jenis kelamin pasien JKN Acute Infarction Myocardial

Tabel 2. Distribusi responden jenis kelamin pasien JKN Acute Infarction Myocardial di

Rumah Sakit Bethesda Yogyakarta 2016

\begin{tabular}{llll}
\hline No & Jenis Kelamin & \multicolumn{1}{c}{$\mathrm{N}$} & \multicolumn{1}{c}{$\%$} \\
\hline 1. & Laki-laki & 35 & $92 \%$ \\
2. & Perempuan & 3 & $8 \%$ \\
\hline & Total & 38 & $100 \%$ \\
\hline
\end{tabular}

Dari tabel 2 terdapat jenis kelamin lakilaki sebesar 35 (92\%) dan jenis kelamin perempuan sebesar $3(8 \%)$.

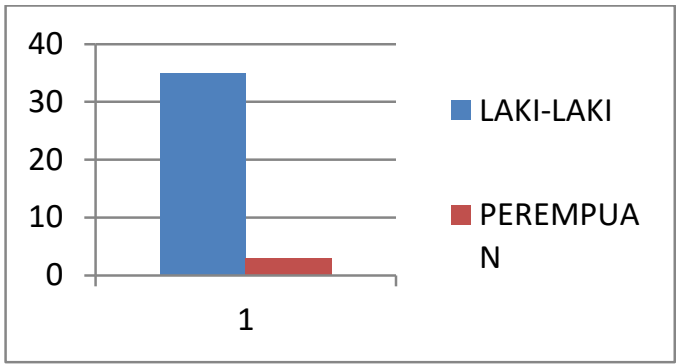

Gambar 2. Persentase jenis kelamin pasien JKN Acute Infarction Myocardial di Rumah Sakit Bethesda Yogyakarta 2016 Sumber: Data primer, 2016.

3. Persentase Umur Pasien JKN Acute Infarction Myocardial

Tabel 3. Distribusi responden umur pasien JKN Acute Infarction Myocardial di Rumah Sakit Bethesda Yogyakarta 2016

\begin{tabular}{clcc}
\hline No & \multicolumn{1}{c}{ Umur } & N & \multicolumn{1}{c}{$\%$} \\
\hline 1. & $\begin{array}{l}\text { Kurang dari sama } \\
\text { dengan 65 tahun }\end{array}$ & 24 & $63 \%$ \\
2. & Lebih dari 65 tahun & 14 & $37 \%$ \\
\hline & Total & 38 & $100 \%$ \\
\hline
\end{tabular}

Dari tabel 3, diperoleh hasil bahwa umur kurang dari sama dengan 65 tahun sebesar 24 (63\%) dan umur lebih dari 65 tahun sebesar $14(37 \%)$.

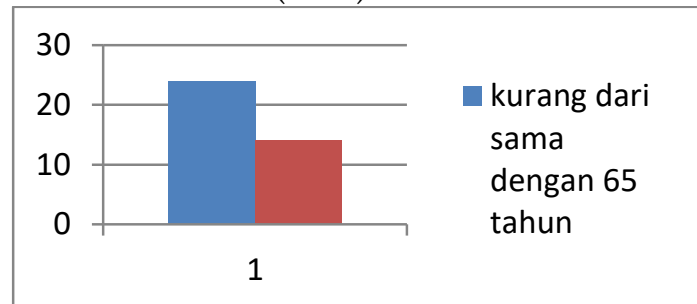

Gambar 3. Persentase umur pasien JKN Acute Infarction Myocardial di Rumah Sakit Bethesda Yogyakarta 2016

Sumber: Data primer, 2016.

4. Hubungan Length of stay, jenis kelamin, dan umur

Tabel 4. Hasil Uji Statistik Hubungan length of stay terhadap biaya

\begin{tabular}{lcccc}
\hline & $\begin{array}{c}\text { Kurang dari } \\
\text { sama dengan } \\
\text { grouper (0) }\end{array}$ & $\begin{array}{c}\text { Lebih dari } \\
\text { grouper } \\
(1)\end{array}$ & $\begin{array}{c}\text { P } \\
\text { value }\end{array}$ & OR \\
\hline $\begin{array}{l}\text { Length } \\
\text { of stay }\end{array}$ & 15 & 10 & 0,0434 & 4,78 \\
$\begin{array}{l}7 \text { hari (0) } \\
\text { Length } \\
\text { of stay > }\end{array}$ & 3 & & 2 & 3396 \\
7 hari (1) & & 10 & & \\
\hline
\end{tabular}


Tabel 5. Hasil Uji Statistik Hubungan jenis kelamin terhadap biaya

\begin{tabular}{lllll}
\hline & $\begin{array}{l}\text { Kurang dari } \\
\text { sama dengan } \\
\text { grouper (0) }\end{array}$ & $\begin{array}{l}\text { Lebih dari } \\
\text { grouper } \\
(1)\end{array}$ & $\begin{array}{l}\text { P } \\
\text { value }\end{array}$ & OR \\
\hline $\begin{array}{l}\text { Peremp } \\
\text { uan (0) }\end{array}$ & 2 & 1 & 0,2295 & 4,76 \\
$\begin{array}{l}\text { Laki- } \\
\text { laki (1) }\end{array}$ & 10 & 25 & & 3366 \\
\hline
\end{tabular}

Tabel 6. Hasil Uji Statistik Hubungan umur terhadap biaya

\begin{tabular}{|c|c|c|c|c|}
\hline & $\begin{array}{c}\text { Kurang dari } \\
\text { sama dengan } \\
\text { grouper }(0)\end{array}$ & $\begin{array}{l}\text { Lebih dari } \\
\text { grouper } \\
(1)\end{array}$ & $\begin{array}{c}\mathrm{P} \\
\text { value }\end{array}$ & OR \\
\hline $\begin{array}{l}65 \\
\text { tahun (0) }\end{array}$ & 7 & 17 & \multirow[t]{2}{*}{0,7281} & \multirow[t]{2}{*}{$\begin{array}{l}0,74 \\
7158 \\
9\end{array}$} \\
\hline $\begin{array}{l}>65 \\
\text { tahun (1) }\end{array}$ & 5 & 9 & & \\
\hline
\end{tabular}

Uji statistik program $\mathrm{R}$ untuk mencari hubungan menggunakan chi-squared test. Nilai yang diharapkan (expected count) dalam tabel kontingensi kurang dari 5, sehingga menggunakan Fisher test. $\mathrm{H}_{0}$ ditolak atau $\mathrm{H}_{\mathrm{a}}$ diterima apabila $p$-value $<$.

Besar $p$-value untuk length of stay yaitu 0,04342 dengan tingkat signifikansi $=0,05$, sehingga terdapat hubungan antara length of stay terhadap biaya pasien. Keeratan hubungan antara dua variabel dilihat dari nilai Odd Ratio (OR) yaitu 4,783396. Hal ini berarti peluang length of stay yang tepat menyebabkan biaya juga tepat sebesar 4,783396 kali lebih besar dibandingkan dengan length of stay yang tidak tepat. Besar p-value untuk jenis kelamin yaitu 0,2295 dengan tingkat signifikansi $=0,05$, sehingga diperoleh hasil bahwa tidak ada hubungan antara jenis kelamin terhadap biaya pasien. Keeratan hubungan antara dua variabel yang diteliti dapat dilihat dari nilai Odd Ratio (OR) yaitu 4,763366. Besar p-value untuk umur yaitu 0,7281 dengan tingkat signifikansi $=0,05$, sehingga diperoleh hasil bahwa tidak ada hubungan antara umur terhadap biaya pasien. Keeratan hubungan antara dua variabel yang diteliti dapat dilihat dari nilai $O d d$ Ratio(OR) yaitu 0,7471589.

\section{Pembahasan}

1. Persentase length of stay pasien dari sampel sebanyak 38 berkas yaitu length of stay kurang dari sama dengan 7 hari sebesar $28(74 \%)$, length of stay lebih dari 7 hari sebesar 10 (26\%). Hal ini berarti bahwa angka length of stay berhasil dibawah angka maksimal perawatan yaitu 7 hari. Semakin panjang lama perawatan maka bisa menunjukan kinerja kualitas medis yang kurang baik karena pasien harus dirawat lebih lama.

2. Persentase jenis kelamin pasien dari sampel sebanyak 38 berkas, terdapat jenis kelamin laki-laki sebesar 35 (92\%), jenis kelamin perempuan sebesar $3(8 \%)$. Penelitian ini sesuai dengan penelitian Natahan di California bahwa peluang jenis kelamin laki-laki lebih besar menderita Acute infarction myocardial daripada perempuan. Namun, penelitian ini tidak sesuai dengan penelitian Pettersen di Norwegia bahwa peluang jenis kelamin perempuan lebih besar menderita Acute Infarction Myocardial daripada laki-laki.

3. Persentase umur pasien JKN Acute Infarction Myocardial di Rumah Sakit Bethesda Yogyakarta 2016. Diperoleh umur kurang dari sama dengan 65 tahun sebesar $24(63 \%)$, umur lebih dari 65 tahun sebesar 14 (37\%). Hal ini sesuai dengan penelitian Alessandro Barchielli di Italy bahwa peluang usia dibawah 70 tahun lebih besar menderita Acute Infarction Myocardial daripada diatas 70 tahun. Namun, hal ini tidak sesuai dengan penelitian Pasquale abete di Italy bahwa peluang usia diatas 65 tahun lebih besar menderita Acute Infarction Myocardial. Selain itu, penelitian ini juga tidak sesuai dengan penelitian Natahan di California bahwa peluang usia diatas 66 tahun lebih besar menderita Acute Infarction Myocardial.

4. Besar $p$-value untuk length of stay yaitu 0,04342 dengan tingkat signifikansi = 0,05 , sehingga diperoleh hasil bahwa terdapat hubungan antara length of stay 
terhadap biaya pasien JKN Acute Infarction Myocardial di Rumah Sakit Bethesda Yogyakarta 2016. Keeratan hubungan antara dua variabel dilihat dari nilai Odd Ratio (OR). Nilai OR yaitu 4,783396. Hal ini berarti bahwa peluang length of stay yang tepat menyebabkan biaya juga tepat sebesar 4,783396 kali lebih besar dibandingkan dengan length of stay yang tidak tepat. Hal ini berarti bahwa angka length of stay berhasil dibawah angka maksimal perawatan yaitu 7 hari. Semakin panjang lama perawatan maka bisa menunjukan kinerja kualitas medis yang kurang baik karena pasien harus dirawat lebih lama. Biaya pelayanan kesehatan masyarakat ialah besarnya dana yang harus disediakan untuk menyelenggarakan dan memanfaatkan pelayanan kesehatan. Semakin tinggi length of stay maka semakin tinggi biaya yang harus dikeluarkan, begitu juga sebaliknya semakin rendah length of stay maka semakin rendah biaya yang dikeluarkan. Hal ini juga sesuai dengan dengan penelitian Jemnser Stenly Iroth bahwa terdapat hubungan antara keduanya, sehingga dengan menurunnya length of stay, maka akan menurunkan biaya perawatan.

5. Besar $p$-value untuk jenis kelamin yaitu 0,2295 dengan tingkat signifikansi = 0,05, sehingga diperoleh hasil bahwa tidak ada hubungan antara jenis kelamin terhadap biaya pasien Acute Infarction Myocardial di Rumah Sakit Bethesda Yogyakarta 2016. Keeratan hubungan antara dua variabel yang diteliti dapat dilihat dari nilai Odd Ratio (OR). Nilai OR yaitu 4,763366. Diperoleh hasil bahwa jenis kelamin tidak mempengaruhi biaya, ada kemungkinan faktor stres yang mempengaruhi length of stay pasien sehingga akan berdampak pada besarnya biaya yang dikeluarkan. Penelitian ini sesuai dengan penelitian

6. Besar $p$-value untuk umur yaitu 0,7281 dengan tingkat signifikansi $=0,05$, sehingga diperoleh hasil bahwa tidak ada hubungan antara umur terhadap biaya pasien JKN Acute Infarction Myocardial di Rumah Sakit Bethesda Yogyakarta 2016. Keeratan hubungan antara dua variabel yang diteliti dapat dilihat dari nilai Odd Ratio (OR). Nilai OR yaitu 0,7471589. Diperoleh hasil bahwa umur tidak mempengaruhi biaya, ada kemungkinan faktor stres yang mempengaruhi length of stay pasien sehingga akan berdampak pada besarnya biaya yang dikeluarkan. Usia merupakan faktor prognostik bahwa pasien lanjut usia memiliki kemungkinan infark yang lebih besar, sehingga menyebabkan komplikasi, komplikasi nini yang akan memperpanjang length of stay, dengan semakin panjangnya length of stay maka semakin tinggi biaya.

\section{PENUTUP}

\section{Kesimpulan:}

1. Besar $p$-value untuk length of stay yaitu 0,04342 dengan tingkat signifikansi $=0,05$, sehingga diperoleh hasil bahwa terdapat hubungan antara length of stay terhadap biaya pasien JKN Acute Infarction Myocardial di Rumah Sakit Bethesda Yogyakarta 2016. Keeratan hubungan antara dua variabel dilihat dari nilai Odd Ratio (OR). Nilai OR yaitu 4,763366. Hal ini berarti bahwa peluang length of stay yang tepat menyebabkan biaya juga tepat sebesar 4,763366 kali lebih besar dibandingkan dengan length of stay yang tidak tepat. Hal ini berarti bahwa angka length of stay berhasil dibawah angka maksimal perawatan yaitu 7 hari. Semakin panjang lama perawatan maka bisa menunjukan kinerja kualitas medis yang kurang baik karena pasien harus dirawat lebih lama.

2. Besar $p$-value untuk jenis kelamin yaitu 0,2295 dengan tingkat signifikansi = 0,05, sehingga diperoleh hasil bahwa tidak ada hubungan antara jenis kelamin terhadap biaya pasien Acute Infarction Myocardial di Rumah Sakit 
Bethesda Yogyakarta 2016. Keeratan hubungan antara dua variabel yang diteliti dapat dilihat dari nilai Odd Ratio (OR). Nilai OR yaitu 4,763366. Diperoleh hasil bahwa jenis kelamin tidak mempengaruhi biaya, ada kemungkinan faktor stres yang mempengaruhi length of stay pasien sehingga akan berdampak pada besarnya biaya yang dikeluarkan.

3. Besar $p$-value untuk umur yaitu 0,7281 dengan tingkat signifikansi $=0,05$, sehingga diperoleh hasil bahwa tidak ada hubungan antara umur terhadap biaya pasien JKN Acute Infarction Myocardial di Rumah Sakit Bethesda Yogyakarta 2016. Keeratan hubungan antara dua variabel yang diteliti dapat dilihat dari nilai Odd Ratio (OR). Nilai OR yaitu 0,7471589. sehingga akan berdampak pada besarnya biaya yang dikeluarkan.

\section{Saran:}

Dari hasil penelitian yang sudah dipaparkan sebaiknya pihak Rumah Sakit meningkatkan pelayanan pasien acute infarction myocardial secara maksimal sehingga bisa menekan angka length of stay dan secara otomatis bisa menekan biaya perawatan yang dikeluarkan. Diperlukan kerjasama yang baik dari semua profesi yang terkait hal ini, serta diperlukan peneltian lebih lanjut untuk diagosisis lainnya sehingga bisa menjadi bahan masukan untuk rumah sakit.

\section{DAFTAR PUSTAKA}

Azwar, A. (1996). Pengantar Administrasi Kesehatan. Jakarta: Binarupa Aksara.

Barchielli, A., Balzi, D., Marchionn, N., Carrabba, N., Margheri, M., Santoro, G.M., Olivotto, I., Buiatti, E. (2007).

Early Discharge After Acute Myocardial Infarction in the Current Clinical Practice. Community data from the AMI-Florence Registry, Italy. International Journal of Cardiology. 114.

Bajzer CT. (2004). Acute Myocardial Infarction.http://www.clevelendclinic meded.com/diseasemanacardiologi/ac utemi/acutemi.htm diakses 24 Desember 2016.

Boersma, E., Mercado, N., Poldermans, D., Gardien, M., Vos, J., \& Simoons, M. L. (2003). Acute myocardial infarction . Erasmus University Medical Center and Thoraxcenter.

Bungin, B. (2005). Metodologi Penelitian Kuantitatif. Jakarta: Kencana Prenada Media Group.

Diehl P.L. (1992). Research Method For Business Management. USA: Macmillan.

Departemen Kesehatan RI. (2009). Profil Kesehatan Indonesia Tahun 2008. Jakarta: Depkes RI.

Departemen Kesehatan RI. (2006). Pedoman Penyelenggaraan dan Prosedur Rekam Medis Rumah Sakit di Indonesia. Jakarta: Depkes RI.

Dinas Kesehatan DIY. (2011). Profil Kesehatan Provinsi DIY. Yogyakarta: Depkes Yogyakarta.

Farissa, P. I. (2012). Komplikasi pada Pasien Infark Miokard Akut ST-elevasi STEMI). Skripsi. Fakultas Kedokteran Universitas Diponegoro. Semarang.

Gray, H.H., Dawkins, K.D., Morgan, J.M., dan Simpson, I.A., (2006). Kardiologi. Jakarta: Erlangga.

Harock. (2004). Psikologi Perkembangan Suatu Pendekatan Sepanjang Rentang. Jakarta: Erlangga.

Hatta, G. R. (2013). Pedoman Manajemen Informasi Kesehatan di Sarana Pelayanan Kesehatan. Jakarta: UI-Press.

Huffman, E. K. (1994). Health Information Management. Berwyn, Illinois: Physician's Record Company.

Hungu. (2007). Demografi Kesehatan Indonesia. Jakarta: Grasindo.

Iroth, J. S. (2016). Dampak Penerapan Clinical Pathway terhadap Biaya Perawatan Pasien Stroke Iskemik Akut di Rumah Sakit Bethesda Yogyakarta. Tesis. Fakultas Kesehatan Masyarakat Universitas Gadjah Mada. Yogyakarta (tidak dipublikasikan). 
Siregar, S. (2013). Metode Penelitian Kuantitatif. Jakarta: Fajar Interpratama Mandiri.

Soewadi, J. (2012). Pengantar Metodologi Penelitian. Jakarta: Mitra Wacana Media.

Kountur, R. (2005). Statistik Praktis. Yogyakarta: Victory Jaya Abadi.

Lemeshow, S. dan David, J. (1997). Besar Sampel dalam Penelitian Kesehatan (Terjemahan). Yogyakarta: Gadjah Mada University Press.

Mahanani, P. S. (2016). Evaluasi Implementasi Clinical Pathway Stroke terhadap Lama Hari Perawatan dan Luaran Klinis Pasien Stroke Non Hemoragik di Rumah Sakit Panti Rapih Yogyakarta. Tesis. Fakultas Kesehatan Masyarakat Universitas Gadjah Mada. Yogyakarta (tidak dipublikasikan).

Nurmayanti. (2014). Perbedaan Lama Perawatan dan Biaya Pasien Stroke Non Hemorrhagic Sebelum dan Sesudah Clinical Pathway di RS Panti Rapih Yogyakarta. Tugas Akhir. Rekam Medis Sekolah Vokasi Universitas Gadjah Mada, Yogyakarta (tidak dipublikasikan).

Notoatmodjo, S. (2012). Metodologi Penelitian Kesehatan. Jakarta: PT. Rineka Cipta.

PERKI. http://www.inaheart.org diakses pada tanggal 30 Maret 2017.

Peraturan Menteri Kesehatan Nomor 269 Tahun 2008 tentang Rekam Medis. www.depkes.go.id. diakses tanggal 10 Desember 2016.

Peraturan Menteri Kesehatan Nomor 52 Tahun 2016. www.depkes.go.id. diakses tanggal 10 Desember 2016.

Peraturan Menteri Kesehatan Nomor 27 Tahun 2014 tentang Petunjuk Teknis Sistem Indonesian Case Base Groups (INA-CBGS). Www.depkes.go.id. diakses tanggal 10 Desember 2016.

Sciagra, R. M., Parodi, G. M., \& Migliorini, A. M. (2010). Evaluation of the Influence of Age and Gender. Journal of Nuclear Cardiology. 444.
Saputra, (2014). Hubungan Lokasi Infark dengan Mortalitas pada Pasien Infark Miokard Akut yang Dirawat di Ruang Intansive Cardiac Care Unit (ICCU) RSU Dokter Soedarso Pontianak.

Sudra, R.I. (2010). Statistik Rumah Sakit. Yogyakarta: Graha Ilmu.

Sultoni, S. (2014). Evaluasi Implementasi Clinical Pathway pada Pasien Acute Myocardial Infarction di Rumah Sakit Umum Pusat Nasional Dr. Cipto Mangunkusumo Jakarta. Tesis. Fakultas Kesehatan Masyarakat Universitas Gadjah Mada. Yogyakarta (tidak dipublikasikan).

Undang-Undang No. 29 Tahun 2004 tentang Praktik Kedokteran diakses tanggal 10 Desember 2016.

Undang-Undang No. 36 Tahun 2009 tentang Kesehatan diakses tanggal 9 Desember 2016.

Undang-Undang No. 44 Tahun 2009 tentang Rumah Sakit diakses tanggal 9 Desember 2016.

Undang-Undang No. 40 Tahun 2004 tentang Sistem Jaminan Sosial Nasional diakses tanggal 9 Desember 2016.

Yusuf, S., Reddy, S., Ounpuu, et al. (2001). General Considerations, The Epidemiological Transition, Risk Factors, and Impact of Urbanization Circulation. Global Burden of Cardiovascular Diseases: 2746-2755.

Yuwono, P. E., Rahardjo, P. M., \& Utami, S. P. (2010). Metode Penelitian Kuantitatif Analisis Isi dan Analisis Data Sekunder. Jakarta: Fajar Inerpratama Mandiri.

Wardani, N.A. (2015). Hubungan Pelaksanaan Clinical Pathway terhadap Lama Ranap dan Kejadian Fatal Pasien Sindroma Koroner Akut. Tesis. Fakultas Farmasi Universitas Gadjah Mada, Yogyakarta (tidak dipublikasikan).

World Health Organization. (2008). World Health Organization Report Tahun 2008, Genewa: 39 World Health Organization. 